\title{
Women who Have Lumpectomy and Radiation Therapy
}

National Cancer Institute

\section{Source}

National Cancer Institute. Women who Have Lumpectomy and Radiation Therapy. NCI

Thesaurus. Code C154232.

The group of women who treat their breast cancer with lumpectomy and radiation therapy. 